\title{
CONSTRUCTIONAL PATTERNS FOR PERCEPTION PREDICATES
}

\author{
Begoña CASASnOVAs GIL \\ Universidad de La Rioja \\ bcasasnovas@gmail.com
}

\begin{abstract}
Firstly, we will look at motivation from a cognitive-linguistic perspective, motivation being understood as how the semantic content in language expressions has an effect on form. Then we shall refer to the factors that constrain the use of expressions of perception in connection with a number of grammatical constructions. Idiomatic expressions have turned out to be very useful in order to look into some constraints that the domain has in terms of the constructional approach. The paper shows how the behaviour of the expressions belonging to the domain of perception in the context of transitivity and intransitivity can be explained if we consider two theories, the Constructional Approach and the standard Conceptual Theory of Metaphor.
\end{abstract}

KEY WORDS: motivation; grammatical construction; transitivity; metaphor; metonymy.

\section{RESUMEN}

Primero nos ocuparemos de la motivación desde el punto de vista lingüístico-cognitivo, según el cuál la motivación se entiende como el efecto que tiene el contenido semántico de una expresión lingüística en la forma. Después pasaremos a referirnos a los factores que restringen el uso de expresiones de percepción relacionadas con un cierto número de construcciones gramaticales. Las expresiones idiomáticas han resultado ser 
muy útiles para investigar las restricciones que el dominio de la percepción tiene en términos del enfoque construccional. El artículo muestra cómo el comportamiento de las expresiones de dicho dominio en función de la transitividad y la intransitividad puede explicarse si consideramos dos teorías, la construccional y la teoría convencional de la Metáfora Conceptual.

PALABRAS ClAVE: motivación; construcción gramatical; transitividad; metáfora; metonimia.

\section{INTRODUCTION: MOTIVATION IN LANGUAGE}

In Cognitive Linguistics, like in functional studies of grammar (including such prominent thinkers as Tom Givón, Michael Halliday, and Simon Dik), syntax is described as motivated by principles that are external to syntax itself. Radden and Panther (2004) give a thought-out overview of the issue of motivation in Cognitive Linguistics. But the issue has a longer tradition.

It has generally been acknowledged that there is a case of motivation in grammar when the relationship between form and meaning is not arbitrary. This may occur because of principles such as iconicity (Haiman, 1980, Givón, 1985) or economy (Givón, 1990). Iconicity is a question of similarity between a sign and the concept that it denotes. Croft (2003: 102) has argued that «the intuition behind iconicity is that the structure of language reflects in some way the structure of experience». We can thus have iconicity of sound (onomatopoeia, as in bang, used to denote the loud noise made by hitting an object violently), of sequence (when the speech sequence is identical to the action sequence, as in An explosion preceded the fire or First there was an explosion and then a fire, but not in A fire followed the thunderstorm), of adjacency (when connected concepts are expressed by adjacent constituents, as happens with relative sentences and their antecedents), and of cohesion (linguistic cohesion guarantees conceptual cohesion). Semantics-syntax isomorphism (one meaning- one form) is also a matter of iconicity where all meaning is expressed syntactically.

Economy is a pervasive phenomenon in language, and in fact it has been argued (Sperber and Wilson, 1995), that it is a universal cognitive phenomenon that shows at all levels of human communication including grammar. For example, linguistic systems (that is, grammars) have anaphoric pronouns and pro-form substitution for the purpose of avoiding repetition (e.g. John is your husband, so John/he has every right to go; John enjoys linguistics more than [he enjoys] literature).

But motivation may also be a matter of core-grammar-external «explanation», i.e. finding out why a certain linguistic element behaves the way it does by looking into semantic and pragmatic meaning or any other factors (e.g. psychological, sociological, cultural). For example, take what Leech (1983: 65) names the end-weight maxim, which is but a pragmatic principle with a universal psychological grounding (as demonstrated by work in psychology; Clark and Clark, 1977). This maxim induces a heavy syntactic constituent to take a right-hand position in English. Thus, the sentence It is on the cards that Simon will resign is easier to process than That Simon will resign is on the cards. The for- 
mer is generally preferred over the latter unless there are other pragmatic principles at work that override this principle (for example, we may want to make emphasis on the heavier constituent). Note that, from a conceptual point of view, that Simon will resign is the event about which we want to say something. On the basis of its nature, it should take subject position. But instead it occupies a complement position, while the empty subject position has been filled in with an expletive (or «dummy» subject pronoun). The motivation for the split construction with an expletive is to be found in a psychological principle dealing with easiness in processing.

In Cognitive Linguistics motivation is additionally studied on the basis of how semantic content has an effect on form. Thus, we may ask ourselves why we associate feelings with heat. This is a case of metaphor with a form of experiential grounding which is also culture-bound (Kövecses, 2005; Lakoff and Johnson, 1999). Thus, in our culture we talk about a heated debate, when the points of view were very different and the debaters used a strong emotional load in their exchanges. The metaphor ANGER IS HEAT is based on the external signs of anger such as redness in the face and excessive perspiration. Also, when someone is friendly, we think of the person as being warm, and cold if the person is distant and offish. The experiential motivation, which has been transmitted culturally, is to be found in people who are physically close (because of friendliness, love, etc.) thus feeling the body heat of each other.

In our previous examination of the semantic make-up of many perception expressions in English we have been able to see how interaction between cognitive models motivates the form of sentences to some extent. For example, as was explained, hold in view derives its meaning from the interaction between an image schema and the notion of control (which ultimately has an image-schematic basis, since control is normally obtained through physical action). The interaction produces enough conceptual material to create a metaphoric source that is put in correspondence with the target concept of 'controlled vision'.

In this section, we are going to look at motivation from a cognitive-linguistic perspective, but in a slightly different way. We will do it by referring to the factors that constrain how we use expressions of perception in connection with a number of grammatical constructions.

\section{WHAT IS A GRAMMATICAL CONSTRUCTION?}

In Cognitive Linguistics there are different ways of understanding the notion of construction. In general, it is accepted that a construction is a form-meaning pairing where the form includes syntax, phonology, prosody, and intonation, while meaning refers to both semantic and pragmatic meaning. Among the construction-grammar proposals we find the following: unification-based frameworks (Fillmore \& Kay, 1988; Kay and Fillmore, 1999), which focus on how to combine constructions to produce full meaning-form representations; the Goldbergian approach, based on the preliminary discussion in Lakoff (1987) (cf. Goldberg, 1995, 2002, 2003, 2005), which primarily investigates networks of connections among argumental constructions (e.g. caused-motion, resultative, transitive, ditransitive) and the way they relate externally, with much emphasis on their psychological validation; Radical Construction Grammar (Croft, 2003), which is typological, fo- 
cuses its attention on the internal structure of constructions; constructions are considered gestalts (or wholes) that can be broken down into parts (unlike other proposals, where constructions are assembled on the basis of putting together their parts); Embodied Construction Grammar (Bergen and Chang, 2002), which has been discussed in the introduction to this dissertation, makes special emphasis on the embodied nature of grammatical constructions; the formalism is similar to the one in unification-based grammars (correlated semantic and syntactic feature matrixes). Langacker's Cognitive Grammar (Langacker, 1987, 1991, 2000) is often cited as a construction-based grammar, since it is based on symbolic associations between form and meaning (which he calls the phonological and semantic poles of symbolic units). Langacker himself points out that Cognitive Grammar is constructional in the sense that it is a non-derivational framework, which describes constructions rather than rules, specifies inheritance mechanisms, deals with composition on the basis of unification, and the correctness of expressions depends on simultaneous constraint satisfaction. However, Cognitive Grammar is symbolic, and as such avoids category labels for grammatical relations (e.g. subject, object, noun, verb, etc.). This is so because grammar does not symbolize semantic structure; rather, semantic structure is a part of grammar (see Langacker, 2005).

In this dissertation, we take sides with the Golbergian notion of construction, but recognize with Ruiz de Mendoza and Mairal (forthcoming), the important role of non-argumental constructions (also called idiomatic, cf. Langlotz, 2006) in meaning construction, even though their interpretation is highly conventional. In fact, as revealed by the analysis in the previous sections of this dissertation, most of the examples of our corpus are highly idiomatic, which does not mean that they are not semantically transparent and therefore capable of conveying a whole range of meaning implications that would be absent from a fully propositional non-transparent version. A framework that allows us to determine all possible meaning implications of an expression is important to understand its meaning potential, very much in the original spirit of Halliday's use of this term, as the ability of an expression to mean in terms of its relationship with other items in a system (Halliday, 1978). In our case, the system is defined by the hierarchy of domains and subdomains established by the onomasiological arrangement of terms supplied by Faber and Mairal (1999). The semantic composition of each idiomatic construction is what allows us to decide its position in the onomasiological hierarchy. The semantic pole of each idiomatic construction, however conventionalized, contains a combination of cognitive models (metaphor, metonymy, image schemas), that can be exploited discursively to make meaning and that is fully meaningful in context. The syntactic pole (together with its phonological and prosodic realization) is highly stable, usually consisting of fixed elements, although it is possible to have some degree of what Ruiz de Mendoza and Mairal (forthcoming) call parametrization (the specification of values which have a degree of genericity, however small it is). Note that in the view supported in this dissertation, the formal aspects of a construction are syntactic (not phonological, since sound patterning is just a way of giving phonic shape to an already determined syntactic string) and these formal aspects consist of parametrizable and non-parametrizable elements. An example is provided by expressions containing the PPs into view/sight and verbs like come and go, which we have dealt with before. Observe the behavior of the constructional pattern by looking into these examples: 
(1) Suddenly, 2000 Indians sprang into view and charged upon the little band from every direction.

(2) Two more attackers ran into view and he leapt to meet them.

(3) From there, the galaxies, M84 and M86, popped into view.

(4) The breed first came into our notice when we were on holiday in Scotland

(5) This plant first came into notice in Britain in 1829.

(6) The incident came into perspective: the truth dawned upon her.

(7) As I raised myself up, sand dunes came into vision.

From examples like spring/run/pop/ into view/sight, we may incorrectly come to the conclusion that the part of the verbal predicate is less variable than the PP. In fact, both elements take a degree of variable parametrization, which means that the construction would need to be enunciated in a more generic way than simply come/go into sight/view. The PP can be realized by items such as notice, (possessive) notice, perspective, and vision. Of course, it is not an argumental construction, like caused-motion and others like this one, which have a large degree of parametrization variability (there are many possible ways of realizing each constructional element), but it should have a less specific formulation than what may be seem at first sight. We propose: *COME/*GO + PP (*vision'), where COME and GO stand for any verb that complies with the basic core meaning of motion toward or away from a deictic center (proximal or distal motion), the asterisk indicates that the verbs have to be adapted ad hoc to the following PP, and the predicate between brackets is any parametrization of the PP that belongs to the domain of vision and, as the asterisk marks again, is compatible with the verbal predicate.

The use of capital letters and an asterisk is common in the more recent versions of Relevance Theory in pragmatics (cf. Carston, 2002; Sperber and Wilson, 1998, Wilson and Sperber, 2002) to signal the creation of a concept during the production or comprehension processes in compliance with the Principle of Relevance. This principle regulates all of human communication and is what leads language users to shape their utterances with the trust that the utterances will be assumed to be optimally relevant. In the process of searching for the relevance of an expression it may be necessary to make meaning adaptations that are relevant with the whole context of assumptions that speaker and hearer believe they share. For example, the adjective good takes on different meanings in the phrases a good game ('enjoyable'), a good teacher ('competent'), a good nun ('charitable'). In the case of the construction that we propose, the meaning adaptation has to be done not only in connection with the external context of the utterance, but also on the basis of the internal compatibility with the PP. The notation of the PP specification uses an asterisk, because it has to be equally adapted internally to the rest of the constructional elements, and a primed predicate. This notation is inspired in the Role and Reference Grammar use of primitive predicates to account for the meaning of lexical items (van Valin and La Polla, 1997; van Valin, 2005). In this case, *vision' represents a finite class of adaptable items related to the notion expressed by this predicate.

Now we have determined some aspects of the constructional nature of the expressions in our corpus on perception, it is necessary to take one more step and investigate in what way these expressions can be coerced to depart from their core use into different uses that are compatible with argumental constructions like the inchoative, and the transitive. 


\section{Perception AND tRAnSitivity}

Generally speaking, perception expressions have a semantically transitive nature. However, transitivity in this semantic domain is not like transitivity in other domains. Compare:

(8) I saw the boy

(9) I struck the boy/the ball

(10) I blew the candle

The difference between strike and see in connection to transitivity is clear. In the case of strike, the object is affected by the action; if we have a perception verb, the object is experienced perceptually by the subject, but is not affected in any way by it. In the case of blow, we have an effect on the object too, but the effect is not like the one in strike:

(11) The girl blew my picture off the desk.

(12) The bully*? struck the little boy out of the yard.

While blow is by nature a caused-motion verb, hit is not. But the action of striking can cause motion under certain circumstances. Godlberg (1995: 170) has argued, following Jackendoff (1990), that strike (unlike hit) is a verb where the impacted entity does not move. This is not exactly true, since corpus data reveal that while we cannot say *He struck John out of the field, we can say He struck the ball out of the field. The rule seems to be that we need to take the nature of the object into account: it is easy to strike a ball and make it move, but this is not the case with a person, who is affected differently by the same action.

Since the caused-motion construction is based on prototypical transitivity, in principle it should not be possible to use it with perception predicates (whether propositional or idiomatic):

(13)* I observed/spotted/noticed/smelled/ touched her out of the room.

However, this is not really the case. The following are attested sentences:

(14) They both slept in my room, although he must have stared her off the bed.

(15) Not only is each person being «listened into being» by the other, they are also «speaking themselves into existence».

(16) She was gazed into it.

These sentences are possible to the extent that the meaning of the verb can be seen as if it were a prototypically transitive verb. This is possible only in those cases where the verb can have an effect on the object that will cause the object to move, even if by itself (what we can call self-instigated motion). Ruiz de Mendoza and Mairal (2007) have treated similar examples as instances of high-level metaphor, where the source domain con- 
tains an «effectual action». This action is what we have referred to here as a «prototypically transitive action», that is to say, one where the agent does have physical impact on the object (if it is to appear in the caused-motion structure, the impact should be capable of moving the object). The target domain can be other types of action, such as an experiential action (e.g. «laugh», in They laughed him out of the room; also applicable to perception verbs if the object somehow «feels» affected by the perceiver) or even an activity (e.g. «drink», in He drank himself into a stupor). Obviously, the verbs in our examples above (stare, listen, gaze) have an intentionality ingredient that makes them more likely to be used in the caused-motion construction. In my view, it is this ingredient that allows the sentences using these verbs to fulfill the Extended Invariance Principle and the Correlation Principle. These principles (c.f. section 2.5. herein), which have been discussed by Ruiz de Mendoza and Mairal (2007) in their application to metaphor and metonymy, are constraining factors. They license some metaphoric and metonymic productions while blocking others. For example, they would block the use of «observe» or «smell» with the caused-motion construction because these verbs resist a metaphorical operation with an effectual action in the source. Since effectual actions are intentional in reference to their effect on the object and these verbs do not exhibit that kind of intentionality, the metaphor cannot take place and the incorporation of the verb into the construction becomes impossible. The situation is very different with the other verbs, because we can correlate the intentionality of the source with that of the target. Then Invariance is obeyed. The Correlation Principle says that we have to find the best possible source domain correspondences for each target element. In the case of perception predicates, we cannot have effectual objects (objects that receive a physical impact that affects them) but we can have special percepts that can act as if affected in the same way. This is easier if the perceiver develops an intentional action. An effectual object is the best source correspondence for an intentional object in the target if we want to mean that the target object felt compelled to move.

An interesting case of caused-motion with perception predicates is provided by the verbs see and show:

(17) It was with a gentle delicacy of manner [...] that he showed her out of the office.

(18) He saw her into the car.

The verb show can be used to mean 'usher' or 'show the way to', and the verb see can have the meaning of 'accompany' or 'escort someone to a place'. It could be argued that the sentences above are not examples of the caused-motion construction on the basis that what they do is simply use a different sense of the verbs show and see, which happen to be associated with a different syntactic structure. This would be the standard projectionist explanation, which has a long tradition in formal Levin and Rappaport, 1995; Rappaport and Levin, 1998) and functional linguistics (Dik, 1997; Van Valin and LaPolla, 1997, van Valin, 2005). The syntactic projection of the verbs in question would be S-VO-PP. A minor problem with this approach resides in the multifarious realizations that we can have for the PP (since we have any preposition indicating motion). This problem can be resolved by simply using the feature [motion] as a collocational constraint on the PP 
slot. A major problem is the impossibility of setting up an important meaning generalization that comes from the semantic features of the caused-motion construction. In her study of this construction Golberg (1995) postulates a number of meaning generalizations that capture the kinds of situation in which the construction is used. One generalization, for example, is that the object (or theme argument in Goldberg, 1995) does not make a cognitive decision in relation to movement (e.g. They frightened her out of the house, but *They persuaded her out of the house). Another generalization is that the object is presumed to move into the specified location: Sam asked John into the room presupposes that John went into the room; it is not possible to say *Sam begged John into the room, since begging someone to do something does not presuppose that the requested action will be carried out. A third generalization is that it is not possible to specify a path of motion if the verb implies an effect other than motion. The idea behind this generalization is that motion along a path is a result of the verbal action and if the verb already implies another result different from motion, there can be an incompatibility: *He spanked the child into the room (since spanking has physical and psychological effects on the child other than motion). The generalization that interests the present discussion most, however, is the observation that the caused-motion construction admits non-direct conventional causation. Take the following example:

\section{(19) The CIA kidnapped German citizen Khaled Masri in 2004 and flew him to Afghanistan for severe interrogation}

The causative use of the verb fly in this example is not very different from the causative uses of show and see above. In 'fly someone to' the agent is not the direct causer of motion, but rather the instigator. The same happens with show and see, where the agent simply induces the object to move but does not act on it physically. Ruiz de Mendoza and Pérez (2001) have treated transitive uses of verbs like fly (which is prototypically intransitive) as examples of the high-level metonymy ACTIVITY FOR CAUSED EVENT (e.g. John walked the dog). In the theory put forward by these authors, there is an activity (e.g. flying, walking), typically involving someone doing something, that affords access to a more complex event in which there is also an instigator of the action. It is important to note that 'walking a dog' or 'flying a person' actually express causation, but they mean more than simply 'causing a dog to walk' or 'causing a person to fly (e.g. in a plane)'. In the first case, the instigator of motion is interpreted as involved in the dog's action (usually the dog's owner accompanies the dog). In the second case, the instigator makes arrangements so the person can take a flight.

We observe similar meaning implications in the causal uses of the verbs show and see: there is an instigator of motion that makes acts on the object in such a way that the object will feel compelled to move in the direction specified. But there is a difference: walk and fly indicate manner of motion, while show and see only indicate perception. In fact the causative show is a short form of 'showed the way to', which is a metonymy for 'invited someone to go somewhere or in a given direction by showing him/her the way'; on the other hand, the causative use of see indicating 'accompany' seems to be a metonymic development of the meaning of this verb as 'make sure that', which is itself a metonymy of the central purely perceptual meaning of see as 'become aware by using the 
sense of vision'. According to this metonymic chain, we can paraphrase I'll see you to the door as 'I'll make sure that you reach the door by accompanying you'. Finally, it is obvious that these metonymic extensions are all low-level metonymies. The high-level metonymy that licenses causal transitivization is ACTIVITY FOR CAUSED EVENT. We find strong parallels between different uses of different verbs. So, the analysis presented here has the advantage of being more elegant in terms of economy and explanatory adequacy than a standard projectionist account that postulates separate senses and syntactic projections for these verbs.

\section{Perception AND INTRAnsitivity}

Since perception is not possible without an object of perception, it might seem pointless to discuss intransivization in this domain. But this is not the case. Intransitivization is very important when it is necessary to give emphasis to the visibility of the object, as is evidenced by the appearance of the verb show in the middle construction:

\section{(19) I wasn't as sharp, and my abs didn't show well}

The competitor in this example complains that his abdominal muscles were not as visible as he would have liked them to be. The causative counterpart loses this form of conceptual prominence:

\section{(20) I wasn't as sharp, and I couldn't show my abs well}

The emphasis in the transitive version is on the effort made by the competitor to show his abdominal muscles, but not on the visibility itself.

In English intransivization is achieved by forcing a transitive verb into an inchoative or a middle construction (cf. Levin, 1993, for details on how the two constructions alternate). The inchoative construction expresses as a process what in real life is an action on an object. For this meaning effect to take place, it is necessary to omit the true agent and to present the object as if it were the agent (which is achieved by making it occupy the subject position in the sentence):

The wind/the cat/John opened the door [causative]

The door opened the door [inchoative]

Ruiz de Mendoza and Mairal (2007) claim that the causative/inchoative alternation is constrained by the high-level metonymy PROCESS FOR ACTION ${ }^{1}$. The application of

\footnotetext{
${ }^{1}$ «Ruiz de Mendoza and Pérez (2001) used the reverse label, ACTION FOR PROCESS, which focuses not on the processing perspective but on the grammatical origin of the alternation (a transitive verb denoting an action becomes intransitive, thus denoting a process). In the processing view, the linguistic expression denoting a process gives access to an implicit action (a source-in-target metonymy). Our discussion requires the processing perspective since we are dealing with the issue of how constructions coerce verbal structure on the basis of conceptual adaptation.»
} 
this metonymy is useful to systematize the meaning implications of inchoative uses of transitive verbs: the actual agent is backgrounded and the object acquires agent-like features.

The middle construction is conceptually more complex. It contains an evaluative ingredient, which may have either the process or the outcome of the process within its scope. Ruiz de Mendoza and Mairal (2007) argue that this evaluative ingredient activates a second metonymic operation. As a consequence, the middle construction is grounded in a double metonymy or metonymic chain: PROCESS FOR ACTION FOR RESULT. In some uses of the construction, the process is highlighted (i.e. gets conceptual prominence) while in others it the result that is highlighted. When we have conceptual prominence on the process, it is possible to paraphrase the middle construction by means of an anticipatory it cleft structure:

(21) The door opened easily

(22) It was easy to open the door

If it is the result that is highlighted, such a paraphrase is not possible:

(23) The meat cooked well.

(24) *It was well to cook the meat.

Heyvaert (2003) has discussed the middle construction from the perspective of Cognitive Linguistics. She observes that the construction goes beyond the traditionally accepted «facility-oriented» use (the ones that we can paraphrase with the cleft sentence). We can have other evaluative elements:

(25) This car handles like a sports sedan

(26) This item ships within 2-3 days

(27) This book sells better than the others

In the case of perception, there is no clear inchoative use of the verbs within the domain. However, the use of the middle construction is not infrequent:

(28) It smelled like old people

(29) It felt really soft

(30) Many of the players just didn't show well

(31) The rice tasted great

However, the examples are restricted to a few verbs, which besides cut across Faber and Mairal's (1999) onomasiological classification. Thus, smell is defined like scent as 'to become aware through one's nose', as belonging to the same lexical domain. But we have not found occurrences of scent in the middle construction (*It scented great), probably because it carries a built-in evaluative element (a scent is pleasant by definition). The same applies to sniff (*It sniffed great), perhaps because it focuses on the manner of smelling, which clashes with an evaluative focus within the same expression. Another ex- 
ample is provided by feel, which belongs with touch to the same domain ('to become aware by using one's hands'). However, feel makes emphasis on the manner of touching (with the intention of evaluating the tactile properties of the object), while touch simply suggests contact. For this reason, we find feel but not touch in the middle construction (*This velvet touches soft). With these data in mind, it is evident that the constructional ascription of perception verbs with respect to the inchoative and middle constructions is verb-specific and very restricted. The situation is different with verbs from other classes. Thus, Ruiz de Mendoza and Mairal (2007b) observe that break and destroy, which have an obvious semantic similarity, do not work in the same way when we try to make them intrasitive:

(32) The child broke the piggy bank > The piggy bank broke

(33) The strike force quickly destroyed the reactor site $>*$ The reactor site destroyed

The reason is that while both verbs have to do with causing damage, they belong to different verb classes: destroy is an existence verb; break is a change of state verb. Some verbs of damage pattern like break and some like destroy:

-Break-verbs:

(34) She shattered the vase $>$ The vase shattered

(35) He split the board $>$ The board split

(36) The roots cracked the wall $>$ The wall cracked

-Destroy- verbs:

(37) She smashed the vase $>*$ The vase smashed

(38) The City demolished the building $>$ *The builging demoslished

(39) The child erased the board $>*$ The board erased

We may wonder about the reason why perception predicates do not combine well with the inchoative construction. This construction treats the object as if it were an agent. Since in perception predicates the object is purely experiential (there is no acting on the percept), there is a clash with the action-oriented semantic structure of the inchoative construction. Then, we may wonder about why we can have some middle uses of perception predicates. The middle construction, like the inchoative, places the object in subject position. But the subject of middles does not acquire any agent-like properties: the semantic object becomes a subject because its relationship with the verb, including the outcome of this relationship is going to be evaluated (e.g. in This book sells well, we focus on evaluating the outcome of selling the object, the book).

The next question is about idiomatic expressions like come into view, go out of sight, and related ones (see section 5.2.3.). These expressions are the idiomatic correlates of intransitive verbs (e.g. appear, show up). They can have causative counterparts: e.g. bring into view, put out of sight. But since these are not cases of a causative configuration being converted into a non-causative, it follows that these idiomatic expressions are not inchoative. Note that in their intransitive-like form they cannot have intentional doers: 
The whale came into view (the whale accidentally moved to a position in which it could be seen). In the causative form, the subject becomes the object of a caused action and at the same time the object of perception: The whale was brought into view (someone caused the whale to be seen). This is precisely the reason for these idiomatic expressions: to conflate two roles in the same expression. For the construction with «come/go», the subject takes the roles of non-intentional doer and of perceptual object; for the causative version with «bring/put» the subject is the object of a caused action and the object of a perceptual experience.

\section{ConClusion}

This chapter has discussed the relationship between perception predicates and some grammatical constructions. In doing so, idiomatic expressions have been very useful to cast some light on the processes which take place and the constraints that the domain of perception has in terms of the constructional approach.

First, we have analyzed the construction COME/GO + PP (*vision). We have studied its uses and its compatibility with argumental constructions. Later we have moved on to the issue of transitivity as the basis of the caused-motion construction, to show that, although perception predicates are not prototypically transitive, since the object is not affected by the action of the verb, there exist some instances of these kinds of verbs taking part in caused-motion constructions. Ruiz de Mendoza and Mairal (forthcoming) have argued that what makes the use of the motion-construction possible is the intentionality of the predicates. A metaphorical operation based on an effectual action is needed so that the construction can be combined with the verbs. With perception predicates we do not have effectual objects; that is, objects do not receive physical impact, which is the reason why it is more difficult for predicates of this kind to be part of the caused-motion construction. The constructional approach and the standard Conceptual Theory of Metaphor merge to explain this phenomenon.

In the same fashion, intransitivity is closely connected to the inchoative construction, but this time a metonymic operation turns out to be necessary to make the construction possible. The metonymy which is at work is PROCESS FOR ACTION FOR RESULT. The inchoative construction treats the object as if it were an agent, whereas in perception predicates the object is purely experiential. As a result of this, perception predicates do not combine well with the inchoative construction, which is very restricted and verb specific.

\section{REFERENCES}

Bergen, Benjamin and Nancy Chang (2002): «Embodied Construction Grammar in simulationbased language understanding». Technical Report TR-02-004, International Computer Science Institute.

—, (2005): «Embodied Construction Grammar in Simulation-Based Language Understanding». In J.-O. Östman and M. Fried (eds.), Construction Grammars: Cognitive Grounding and Theoretical Extensions, Amsterdam, John Benjamins 
CARSTON, Robyn (2002). Thoughts and utterances: The pragmatics of explicit communication, Oxford, Blackwell.

Clark, Herbert H. and Eve V. Clark (1977): Psychology and Language: An Introduction to Psycholonguistics, New York, Harcourt Brace Jovanovich.

Croft, William (2003): Typology and universals, 2nd ed., Cambridge, Cambridge University Press.

DIK, Simon C. (1997): The theory of functional grammar. Part 1: The structure of the clause, Second, revised edition prepared by Kees Hengeveld, Berlin, Mouton de Gruyter.

FILLMORE, Charles, Paul Kay and Mary Catherine O’Connor (1988): «Regularity and Idiomaticity in Grammatical Constructions: The Case of let alone», Language 64, pp. 501-538.

GIVÓN, Tom (1985): «Iconicity, isomorphism and non-arbitrary coding in syntax». In Haiman, John (ed.) (1985): Iconicity in syntax, Amsterdam, Benjamins.

—, (1990): Syntax: A functional-typological introduction. Vol. II, Amsterdam, Benjamins.

Goldberg, Adele E. (1995): Constructions: A Construction Grammar Approach to Argument Structure, Chicago, University of Chicago Press.

-, (2002): «Surface generalizations: An alternative to alternations», In Cognitive Linguistics 134, pp. 1-31.

-, (2003): «Constructions: a new theoretical approach to language», Trends in Cognitive Sciences 7(5): 219-224.

-, (2005): Constructions at work: the nature of generalization in language, Oxford, Oxford University Press.

HAIMAN, John (1980): «The iconicity of grammar: isomorphism and motivation», Language 56 (3), 515-540. 2003

HallidAY, Michael A. K. (1978): Language as Social Semiotic. London: Edward Arnold.

Heyvaert, Liesbet (2003): A Cognitive-Functional Approach to Nominalization in English, Berlin/New York, Mouton de Gruyter.

KAY, Paul \& Charles J. Fillmore (1999): «Grammatical constructions and linguistic generalizations: The 'What's X doing Y' construction», Language 75: 1-33.

KöveCSES, Zoltan (2005): Metaphor in Culture, Universality and Variation, Cambridge, Cambridge University Press.

LANGACKER, Roald W. (2005): «Construction Grammars: cognitive, radical, and less so», In Cognitive Linguistics. Internal Dynamics and Interdisciplinary Interaction, Francisco Ruiz de Mendoza and Sandra Peña (eds.), 101-159, Berlin/New York, Mouton de Gruyter.

LANGlotz, Andreas (2006): Idiomatic Creativity. A Cognitive-Linguistic Model of Idiom-Representation and Idiom-Variation in English, Amsterdam/Philadelphia, John Benjamins.

LEECH, Geoffrey (1983): The Principles of Pragmatics. London/New York: Longman.

Levin, Beth (1993): English Verb Classes and Alternations. A Preliminary Investigation, Chicago/London, The University of Chicago Press.

Levin, Beth and Malka Rappaport (1995): Unnaccusatives: At the Syntax-Lexical Semantics Interface, Cambridge, Mass., The MIT Press.

RAdDEN, Günter and Klaus-Uwe Panther (2004): «Introduction: Reflections on motivation», In Radden, Günter and Klaus-Uwe Panther (eds.) Studies in Linguistic Motivation, Berlin/New York, Mouton de Gruyter; pp. 1-46.

RAPPAPORT, Malka and Beth Levin (1998): «Building Verb Meanings», en M. Butt y W. Geuder (eds.) The Projection of Arguments: Lexical and Compositional Factors, CSLI, Stanford, pp. 97-134.

RUIZ DE MENDOZA IBÁÑEZ, Francisco José and Ricardo Mairal Usón (2007b): «Levels of semantic representation: where lexicon and grammar meet», Revista Interlingüística, 17.

_, (forthcoming) «Levels of description and constraining factors in meaning construction: an introduction to the Lexical Constructional Model», unpublished manuscript. 
Ruiz de Mendoza IbáÑEz, Francisco José and Lorena Pérez Hernández (2001): «Metonymy and the grammar: Motivation, constraints, and interaction», Language and Communication 21, pp. 321-357.

SPERBER, Dan \& Deirdre Wilson (1995/1986): Relevance. Communication and Cognition, 2nd. ed. Oxford, Basil Blackwell.

SPERBER, Dan \& Deirdre Wilson (1998): «The mapping between the mental and the public lexicon», In P. Carruthers \& J. Boucher (eds) Thought and language, Cambridge, CUP.

VAN VALIN, Robert D. and Randy J. LaPolla (1997): Syntax. Structure, meaning and function, Cambridge, Cambridge University Press.

Van Valin, Robert D. Jr. (2005): The Syntax-Semantics-Pragmatics Interface: An Introduction to Role and Reference Grammar, Cambridge, Cambridge University Press. 